\title{
NOTÍCIES
}

\section{Jornades d'estudi sobre Gabriel Alomar}

La primera particularitat de les jornades és que no se celebraren en ocasió d'alguna d'aquelles efemèrides (aniversaris rodons, de naixement o de mort) que de costum són la causa originària d'aquesta mena d'activitats acadèmiques. La motivació per organitzar-les va ser la certesa existent dins el món acadèmic que Alomar és encara avui molt més desconegut del que, per la seva rellevància com a intel·lectual i escriptor, hauria de ser. Durant els primers trenta anys del franquisme, fou com si mai no hagués existit. No es va reeditar ni una sola de les seves obres. Al llarg de la dècada de 1970 es varen començar a produir les primeres iniciatives de recuperació del personatge i dels seus escrits. Des de l'àmbit de la investigació històrico-cultural, hi contribuïren Antoni-Lluc Ferrer, Antoni Serra, Joan Lluís Marfany, Gregori Mir, la revista Lluc... Aquells anys es produïren les primeres reedicions: El futurisme $i$ altres assaigs (1970), La pena de mort (1972) i La columna de foc (1973). I en el terreny de l'activisme civil, de caràcter cultural i polític, Alomar es va convertir en un símbol de les idees d'esquerres i de país. Per això, el reivindicaren l'Obra Cultural Balear, el Congrés de Cultura Catalana i els sectors intel-lectuals més actius en la defensa de la democràcia i de l'autogovern. El trasllat de les seves restes des d'El Caire a Mallorca, l'any 1977, va ser una fita rellevant en la recuperació cívica i política de qui va ser el més il-lustre dels exiliats mallorquins. La dècada de 1980, en el marc polític de la tot just implantada democràcia municipal, començà el seu reconeixement institucional: l'Ajuntament de Palma va posar el seu nom a un tram de les avingudes de Palma, el va declarar fill il.lustre (1983) i va publicar la biografia que en va escriure Antoni Serra (1984). I el Consell de Mallorca, anys més tard, el va declarar fill predilecte de l'illa (2015). A més, les dues darreres dècades s'ha començat a dur a terme el projecte de l'edició de les Obres completes del nostre escriptor, sota la direcció del Dr. Pere Rosselló Bover i amb el segell de l'Editorial Moll o de la Institució Francesc de B. Moll. Fins ara n'han sortit cinc volums, els quals d'entrada tenen un doble mèrit indiscutible: van encapçalats per uns pròlegs extensos i rigorosos, elaborats per estudiosos de la màxima solvència, i ofereixen una gran quantitat de materials, molt majoritàriament de procedència periodística, que per primera vegada es fan fàcilment accessibles als lectors. Els darrers vint anys la bibliografia crítica sobre Alomar i la seva obra ha augmentat de manera molt considerable. Entre altres publicacions, cal esmentar l'edició crítica de La columna de foc (2011), a cura de Rosselló Bover, i la nova biografia que n'han escrit els historiadors Catalina Moner i Jordi Pons (2017).

Ara bé, malgrat el creixement del nombre d'estudis sobre Alomar, a hores d'ara hi continua havent una gran quantitat dels seus articles que encara mai no han estat recollits en cap volum i una bona part de les seves obres d'abans de la Guerra Civil no han estat objecte de cap reedició. Això significa que de la seva producció escrita encara n'ignoram un percentatge prou alt. I d'aquest fet se'n deriva una conseqüència: el coneixement que actualment tenim d'Alomar segueix sent parcial i, per això, no resulta fàcil interpretar, amb garanties màximes d'encert, el seu pensament, la seva trajectòria política, el paper de la seva participació com a agent protagonista dins els corrents ideològics i dins els moviments culturals i sociopolítics amb què va estar en contacte.

Amb la celebració de les jornades d'estudi «Gabriel Alomar (1873-1941): l'intel-lectual, el periodista i el polític» es va pretendre donar una nova empenta a la investigació sobre l'activitat intel-lectual i l'obra 
escrita del personatge. També era una manera d'incitar els investigadors que s'animassin a explorar els nous materials alomarians que amb l'edició dels cinc volums de les Obres completes han passat a ser d'accés fàcil, amb la particularitat, a més, que de l'anàlisi a fons d'aquests materials se'n poden derivar noves interpretacions. Les jornades varen ser promogudes per la Universitat de les Illes Balears (UIB) i per l'Institut d'Estudis Catalans (IEC). De la UIB, hi varen estar implicats la Facultat de Filosofia i Lletres; els departaments de Filologia Catalana i Lingüística General i el de Ciències Històriques i Teoria de les Arts; el Grup d'Estudi de la Cultura, la Societat i la Política al Món Contemporani i el Grup de Recerca Literatura Catalana dels segles XIX i XX (LITERCAT); el Centre d'Estudis i Documentació Contemporània (CEDOC); i el Vicerectorat de Projecció Cultural, Universitat Oberta i Seus Universitàries i el Servei d'Activitats Culturals (SAC). De part de l'IEC, hi va participar la Secció Històricoarqueològica i la delegació de l'entitat a Palma. En varen ser entitats col-laboradores la Regidoria de Cultura, Educació i Benestar Social de l'Ajuntament de Palma, el Departament de Cultura, Patrimoni i Política Lingüística del Consell de Mallorca, les fundacions Ateneu Pere Mascaró i Emili Darder i la Fundació Gabriel Alomar. L'organització va anar a càrrec d'una comissió formada pels doctors de la UIB Sebastià Serra, Damià Pons, Pere Rosselló Bover, Antoni Marimon, Francesca Lladó, David Ginard i Elisabeth Ripoll.

Les Jornades, celebrades els dies 14 i 15 de novembre de 2019, als edificis de Sa Riera (Palma) i Ramon Llull (campus de la UIB), varen incloure dues conferències (Pere Gabriel i Jordi Casassas) i vint-itres ponències. Els temes que s'hi tractaren foren molt diversos, amb l'objectiu de copsar Alomar en la seva totalitat. Val a dir, però, que es va deixar de banda la seva condició de poeta, ja que és recent i molt complet l'anàlisi amb què Rosselló Bover va prologar l'edició crítica de La columna de foc. Les dues conferències es varen orientar a la reconstrucció del trajecte ideològic global d'Alomar, en un cas «en la cruïlla del pensament liberal, nacionalista i socialista, amb algunes referències europees» (Gabriel) i en l'altre en el context «intel-lectual i polític de Catalunya. Des de la militància republicana i catalanista a la Unió Socialista de Catalunya» (Casassas). Els temes de les ponències es poden agrupar en diferents blocs. Un faria referència a la relació i les aportacions d'Alomar als diferents corrents ideològics: el mallorquinisme polític (Bartomeu Carrió), el republicanisme (Antoni Marimon) i el socialisme (Antoni Vidal). Un altre bloc es va referir a l'activitat periodística que va desenvolupar: a Mallorca (Arnau Company), a Catalunya (Sebastià Sansó, Agnès Cerdà i Francisca Niell), a Madrid (Elisabeth Ripoll) i a Buenos Aires (Pilar Arnau). El pensament alomarià va ser interpretat en referència a diferents qüestions: la pedagogia (Bernat Sureda), el laïcisme (David Ginard), les arts plàstiques (Francesca Lladó), «la idea de ciutat» (Oriol Nel.lo i Margalida Mestre), la Revolució Francesa (Pere Salas), la Gran Guerra (Damià Pons), i l'acció política (Catalina Moner i Jordi Pons). A les altres ponències es tractaren altres aspectes diversos d'Alomar: el de crític literari a Los Lunes de El Imparcial (Pere Rosselló Bover), la relació que va tenir amb Antoni M. Alcover (Pilar Perea), la tasca com a docent a instituts de secundària (Gabriel Alomar), l'activitat parlamentària al Congrés dels Diputats (Pere Joan Pons), la seva actuació durant la Segona República i la Guerra Civil (Arnau Company) i el procés de la seva recuperació a partir de 1970 (Sebastià Serra).

El nombre de participants a les jornades, entre els ponents i els inscrits, va ser d'una seixantena. I com que les sessions varen ser obertes al públic, a bona part d'elles també hi hagué assistents esporàdics.

La previsió és que el 2022 es publiqui el volum que arreplegarà els textos de les dues conferències $\mathrm{i}$ de les vint-i-tres ponències. Amb tota seguretat, el seu contingut representarà un salt qualitatiu important en el coneixement d'Alomar, tant del personatge com de la seva obra.

Damià Pons

Universitat de les Illes Balears 